\title{
Biochemical analyses for dental age estimation: a review
}

\author{
Maitreyi Pillalamarri, Ravikanth Manyam º, Swetha Pasupuleti, Smita Birajdar and Satya Tejaswi Akula
}

\begin{abstract}
Background: For various legal and forensic scenarios, establishing an individual's age, both living and dead, plays a crucial role. Various morphological, radiographic, and molecular methods can be used for age estimation. In children and adolescents, age estimation is based on the established developmental stages. However, in adults, where the development ceases into maturation, the degenerative changes play a role in determining the age.

Main body of the abstract: In the natural aging process, several molecular changes occur most commonly in the long-living proteins and hard tissues like the teeth and bone. These molecular changes gradually lead to alterations in several organs and organ systems, which can be quantified and correlated with age, including aspartic acid racemization, collagen crosslinks, advanced glycation-end products, and mitochondrial DNA mutations.

Short conclusion: Among the above methods, the racemization of aspartic acid can be considered as the most precise method. The main advantage of using aspartic acid racemization is that the sample can be collected from tissues (teeth) protected from various environmental and nutritional factors. If all the confounding factors are stable, the utilization of advanced glycation-end products can also be considered valuable. Environmental factors like lead accumulations may also help determine the age. However, further studies need to be conducted, focusing on providing a more standardized method. This review provides a concise summary of the biochemical techniques that can be used for estimation of age.
\end{abstract}

Keywords: Age estimation, Biochemical methods, Aspartic acid racemization, Collagen crosslinks, Advanced glycation-end products, Lead accumulations, mtDNA mutations

\section{Background}

An essential element of the forensic practice is to assign the exact age to both living individuals and human remains. Numerous methods have been proposed for age estimation for various legal, social, and forensic reasons, based on morphology, radiography, and biochemical changes. In children and adolescents, estimation of age is focussed mainly on the various developmental stages a human body undergoes until it completes maturation (Hegde et al. 2017, Ozveren et al. 2018, Demirjian et al. 1973). However, in adults, when development ceases into maturation, the application of these methods is not

*Correspondence: ravikanth.m@vdc.edu.in

Department of Oral and Maxillofacial Pathology, Vishnu Dental College,

Vishnupur, Bhimavaram, West Godavari, Andhra Pradesh 534202, India possible. So, when growth attains maturity, the age estimation is based on degenerative changes in the body (Cameriere et al. 2007). To estimate age in decomposed or skeletonized human remains, and in the absence of soft tissue remains, the bone and teeth are widely used. The majority of age estimation techniques are based on morphological and radiographic changes, may tend to show inconsistent results. The morphological methods are subjective and may give an error of up to ten years (Waite et al. 1999).

In natural aging processes, several molecular changes commonly occur in the long-living proteins. These molecular changes gradually lead to alterations in several organs and organ systems including the teeth and bone. Several such changes have been studied and identified over the years. Aspartic acid racemization, collagen 

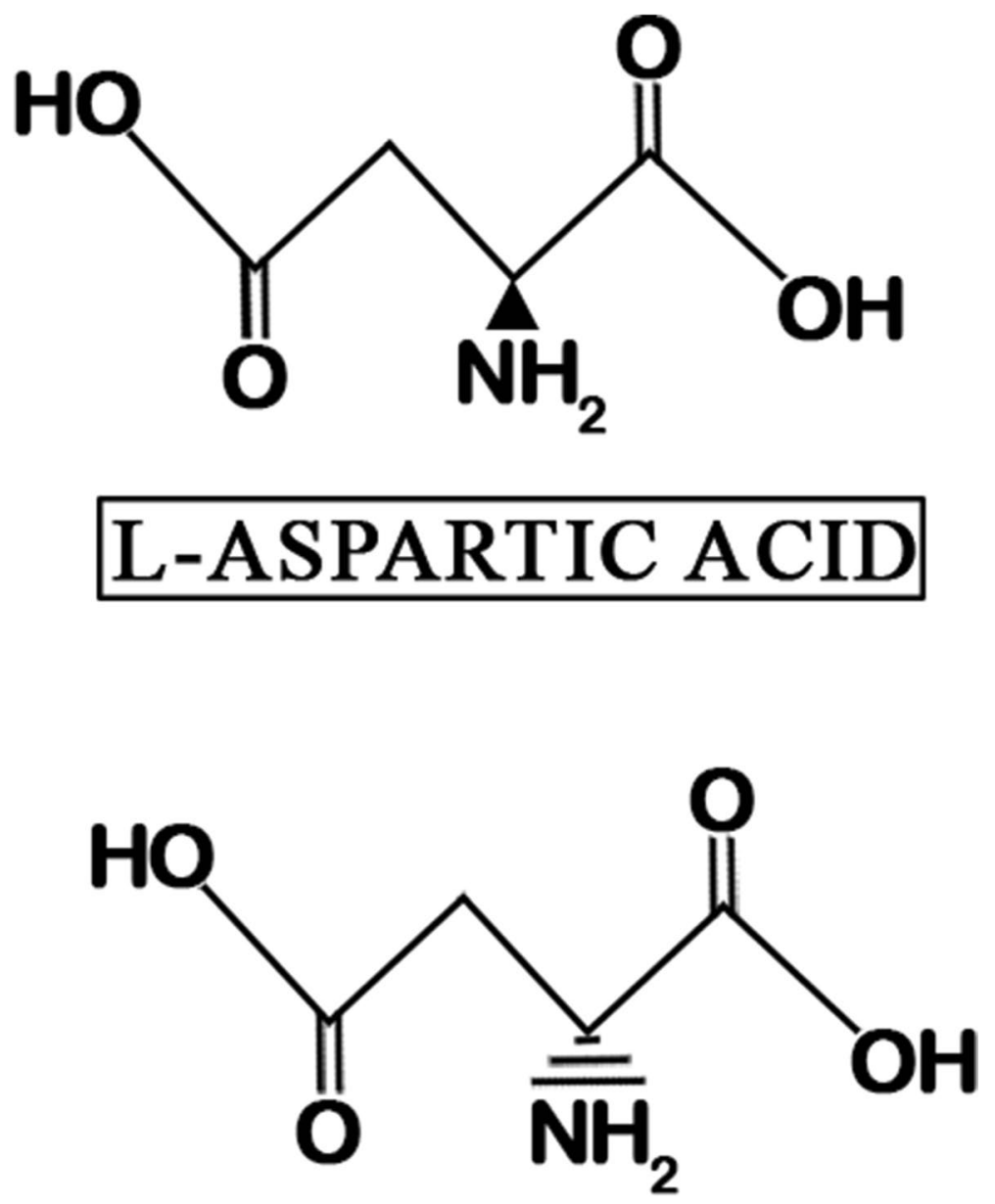

D-ASPARTIC ACID

Fig. 1 Racemization of aspartic acid

crosslinks, advanced glycation-end products, and mitochondrial DNA (mtDNA) mutations are some of the most established methods of biochemical age estimation. The environmental factors, such as lead accumulation, may also play a role in determining the age. The current narrative review describes the various biochemical methods, the methodology, advantages, and drawbacks concisely.

\section{Main text}

\section{Aspartic acid racemization (AAR)}

In most living organisms, optically active amino acids initially consist of only L-forms, which partially get converted into D-forms until an equilibrium is obtained (Ogino and Ogino 1988). Under this equilibrium, the $\mathrm{D} / \mathrm{L}$ ratio of aspartic acid is 1.0 (Ogino et al. 1985). This conversion is known as racemization, which causes alterations in the conformation of metabolically stable proteins, thereby inducing changes in their biochemical activities (Fig. 1). It is temperature, $\mathrm{pH}$, and humiditydependent (Alkass et al. 2010). This phenomenon has been observed in long-living proteins. Among the amino acids, aspartic acid has the fastest rate of racemization, followed by alanine, glutamic acid, isoleucine, and leucine. Therefore, aspartic acid is most commonly used for age estimation. The chemical instability of asparaginyl and aspartyl residues in proteins may result in modifications that increase the D-aspartate residue with age (Geiger and Clarke 1987). Amino acids undergo continuous formation and degradation. In such cases, tissues with long-living proteins and low metabolic rates provide 
more precise results than proteins with high metabolic rates (Alkass et al. 2010).

In humans, the presence of long-living proteins is observed in hard tissues of the teeth, bone (type I collagen, telopeptides, osteocalcin), sclera of the eye (elastin), lung parenchyma (elastin), arterial wall (elastin), and intervertebral disc. It is also observed in articular cartilage (proteoglycans), brain (tubulin, synapsin, proteoglycans, myelin base protein, white matter, $\beta$ amyloid protein, tar protein), ocular lens ( $\alpha$ A-crystallin), cartilage, membrane proteins of erythrocytes, and skin (RitzTimme and Collins 2002).

Even after all other soft tissues have degenerated, hard tissues like the teeth and bone are well preserved. The teeth, in particular, are frequently conserved even when most of the bones have been destroyed or mutilated. In 1975, Helfman and Bada first used the aspartic acid racemization method in dentin to assess age (Helfman and Bada 1975). Subsequently, several studies have been conducted by analyzing various dental tissues like enamel (Griffin et al. 2010), dentin (Helfman and Bada 1976), (Ohtani and Yamamoto 2010; Minegishi et al. 2019), cementum (Ohtani et al. 1995), and using the tooth as a whole unit. The rate of aspartic acid racemization in root dentin was investigated in a Polish population (Wochna et al. 2018), and researchers found a strong correlation (0.96-0.98) between chronological age and aspartic acid racemization levels, with a standard estimation error of 2.95-4.84 years. A correlation between the age of dentin and the extent of aspartic acid racemization was identified to be approximately 0.96 with a standard error of 5.69 years (Ritz et al. 1990).

The extent of post mortem preservation on aspartic acid racemization in the dentin of healthy, impacted, and carious teeth were studied and noted that the teeth can be preserved for up to 10 years, showing a negligible effect on estimated values with an error of 4 years (Ogino et al. 1985). The presence of caries in teeth has been shown to influence the rate of racemization (Griffin et al. 2008). Deviations up to 20.39 years were noted in carious teeth (Sirin et al. 2018). It is assumed that caries induce protein degradation, which thereby generates small fragments of lower steric hints, leading to faster accumulation of D-aspartic acid (Collins et al. 1999). Protein degradation is observed in cases of archaeological tooth samples with long post-depositional intervals, which may lead to the formation of smaller peptide fragments. This may lead to a faster conversion of L-forms to D-forms, resulting in increased accumulation of D-Asp and hence may show false high age at death estimates (Mahlke et al. 2021).

The aspartic acid racemization is also observed in deciduous teeth and a correlation between chronological age and rate of racemization has been identified ( $r=0.824-0.98)$, proving it to be applicable in deciduous teeth (Ohtani 1994).

With the increase in temperature, the extent of aspartic acid racemization increases significantly $(r=0.913$; $p<0.01)$ with heating time, and the stability rates of dentin at different temperatures $\left(22-25^{\circ} \mathrm{C}, 4^{\circ} \mathrm{C}\right.$, and $\left.-30^{\circ} \mathrm{C}\right)$ showed no significant changes after 1 year with an error range of 5 years (Minegishi et al. 2019). The position of teeth and the time taken for dentin formation also influence the rate of racemization and is highest in the first molars in the middle-aged population and second molars in elderly individuals (Ohtani et al. 2003). No differences in racemization rates were noted between the jaws (Rajkumari et al. 2013).

High power liquid chromatography (HPLC) and gas chromatography (GC) are generally used to analyze the racemic mixture. In the various available HPLCs, ionexchange chromatography (IEC) is usually preferred (Kaufman and Manley 1998). The gas chromatographic method is considered as the most sensitive method (Minegishi et al. 2019). The procedure involves acid extraction, which results in two parts: the acid-soluble and the insoluble acid fraction. The soluble acid fraction mainly consists of collagen, and the insoluble fraction consists of non-collagenous proteins. The insoluble acid fraction (collagen) undergoes constant remodeling. The rate of racemization is rapid in the non-collagenous proteins. The $\mathrm{D}$-aspartate accumulates with age predominantly in the non-collagenous proteins (Ritz et al. 1994). Such non-collagenous proteins like osteocalcin are also found in bone, and the extent of aspartic acid racemization using osteocalcin is the measure of the aging of these proteins, thereby measuring an individual's age. However, the correlation between the rate of racemization and age varies with the type of bone used, the highest being in the sternum and the lowest in the pelvic and sacral bone (Ohtani et al. 2002). The alveolar bone, a metabolically more active bone, shows an increased ratio of racemization with age. The rate is significantly higher in males than in females. However, the alveolar bone cannot be used in edentulous individuals (Ohtani et al. 2007).

Non-dental tissues like the yellow ligament of the spine, and sclera, contain long-living proteins like elastin that accumulate $\mathrm{D}$-aspartate residues, making it a suitable testing sample with results closer to the actual age and less time consuming. But during sample collection, elastin's purification is necessary as the AAR is strongly influenced by collagen contamination (Ritz-Timme et al. 2003). However, it is not reliable for corpses under the influence of high temperatures (Klumb et al. 2016). Evidence suggests that this method is highly accurate and precise in determining the age in both humans and 
cadavers with an error of fewer than \pm 3 years (Ohtani and Yamamoto 2010).

\section{Collagen crosslinks}

The central portion of type I collagen has a triple-helical structure to stabilize the collagen network between which covalent crosslinks exist (Eyre 1987). These reducible crosslinks are present in newly synthesized collagen. Their proportion rapidly increases during the growth phase to reach a maximum. As the growth rate slows down, the proportion of these crosslinks decreases and forms a mature non-reducible crosslink (Robins et al. 1973). These age-related changes are observed in the skin (Robins et al. 1973), dentin (Mechanic et al. 1971), and cartilage (Eyre and Oguchi 1980).

The crosslink patterns are characteristic and are formed by two divalent crosslinks of dehydro-dihydroxylysinonorleucine and dehydro-hydroxylysinonorleucine. The bone and dentin collagen also contain two non-reducible crosslinks of hydroxypyridinium, namely pyridinoline and deoxypyridinoline. The calcified tissues of bone and teeth show a significant peak in lysyl hydroxypyriidinium residues (Eyre et al. 1984).

Pyridinoline is a non-reducible crosslink, which is the main maturation product of reducible crosslinks prominent in bone and dentin (Fugimoto et al. 1978). It has a 3-hydroxypyridinium ring with a three side-chain that embodies their hydrolysine residues. It is abundant in adult cartilage at one residue per collagen molecule. Almost all reducible crosslinks in cartilage collagen seem to progress rapidly to hydroxypyridinum crosslinks. Deoxypyridinoline has been identified as a minor component in the adult dentin residues.

The correlation between collagen crosslinks and age has been studied, and it was observed that the hydroxypyridinium crosslinks increased with age (Walters and Eyre 1983). Evaluation of deoxypyridinoline crosslinks from dentin can show an error of 14.9 years (Martin-De Las Heras et al. 1999). Analysis of these crosslinks is studied using enzyme immunoassay and chromatography.

Analysis of dentin at different ages, therefore, is a useful index of the rate of maturation of hydroxylysine-based crosslinks in collagen fibrils. However, the estimated age can have a high error rate. Standardization needs further research.

\section{Advanced glycation-end products (AGEs)}

Louis-Camille Maillard, in 1912, discovered that when amino acids are heated in the presence of reducing sugars, they turn brown. This biological process results in the formation of advanced glycation-end products, known as Maillard reaction. It involves a non-enzymatic reaction of the blood glucose with body proteins, which leads to a cumulative modification of tissue proteins throughout the body (Tessier 2010). Maillard reaction can be described in three stages: early, intermediate, and late stages (Singh et al. 2001). In the early stage, reducing sugars like glucose, fructose, mannose, and galactose react with different molecules like proteins, nucleic acids, and lipids to form a stable ketoamide called Amadori compound. In the next stage, this Amadori compound further degrades into various carbonyl compounds like glyoxal, 3-deoxyglucosone, and methylglyoxal. The final stage involves reactions between the carbonyl compound with amino acids, leading to complex rearrangements, cleavage, and covalent binding reactions of the Amadori products (Fig. 2). This Amadori arrangement is irreversible and results in the formation of stable adducts and protein crosslinks called advanced glycation products (Schleicher and Wieland 1986).

Various end products including pentosidine (Sell and Monnier 1990), fructoselysine (Lyons et al. 1991), and $\mathrm{N}^{€}$-carboxymethyl lysine (CML) (Fu et al. 1996) have been analyzed. These AGEs accumulate in long-lived proteins. They can cause tissue damage and may also contribute to the development of complications in diabetes mellitus (Brown et al. 2005), atherosclerosis (Brownlee 1994), aging (Fu et al. 1996), and Alzheimer's disease (Vitek et al. 1994). Systemic conditions like advanced renal diseases, hypertension, inflammation, oxidative stress, and hyperglycemia also accelerate the formation of AGEs (Singh et al. 2001). The formation of these products in vitro and in vivo is turnover dependent on the chemically modified protein target and sugar concentration. These AGEs easily bind to collagen and act as a crosslink between the collagen fibrils in collagen-rich tissues like the crystalline lens (Lyons et al. 1991), articular cartilage, aorta (Oimomi et al. 1989), rib cartilage, skin collagen (Dyer et al. 1993), intervertebral disc, and dentin.

Along with nutrients, dentin also receives AGEs from the blood vessels. They form crosslinks with collagen fibers and induce various mechanical and morphological changes in dentin, along with brownish discoloration (Ilea et al. 2018). By analyzing the degradation of dentin collagen by carboxylic protease, the characteristic Maillard fluorescence can be noticed (Kleter et al. 1997). An early Maillard reaction product, called furosine, has been examined in healthy and carious dentin (Kleter et al. 1998). AGEs like CML get accumulated in dentin physiologically, which can be used for analysis (Miura et al. 2014). Pentosidine levels in root dentin (including healthy, diabetic, stored, and heated root dentin) can be quantified and used for age estimation. Heated and carious teeth show high levels of pentosidine (Greis et al. 2018). In cases of long post-depositional intervals, pentosidine levels remain stable in the dentinal collagen. It 


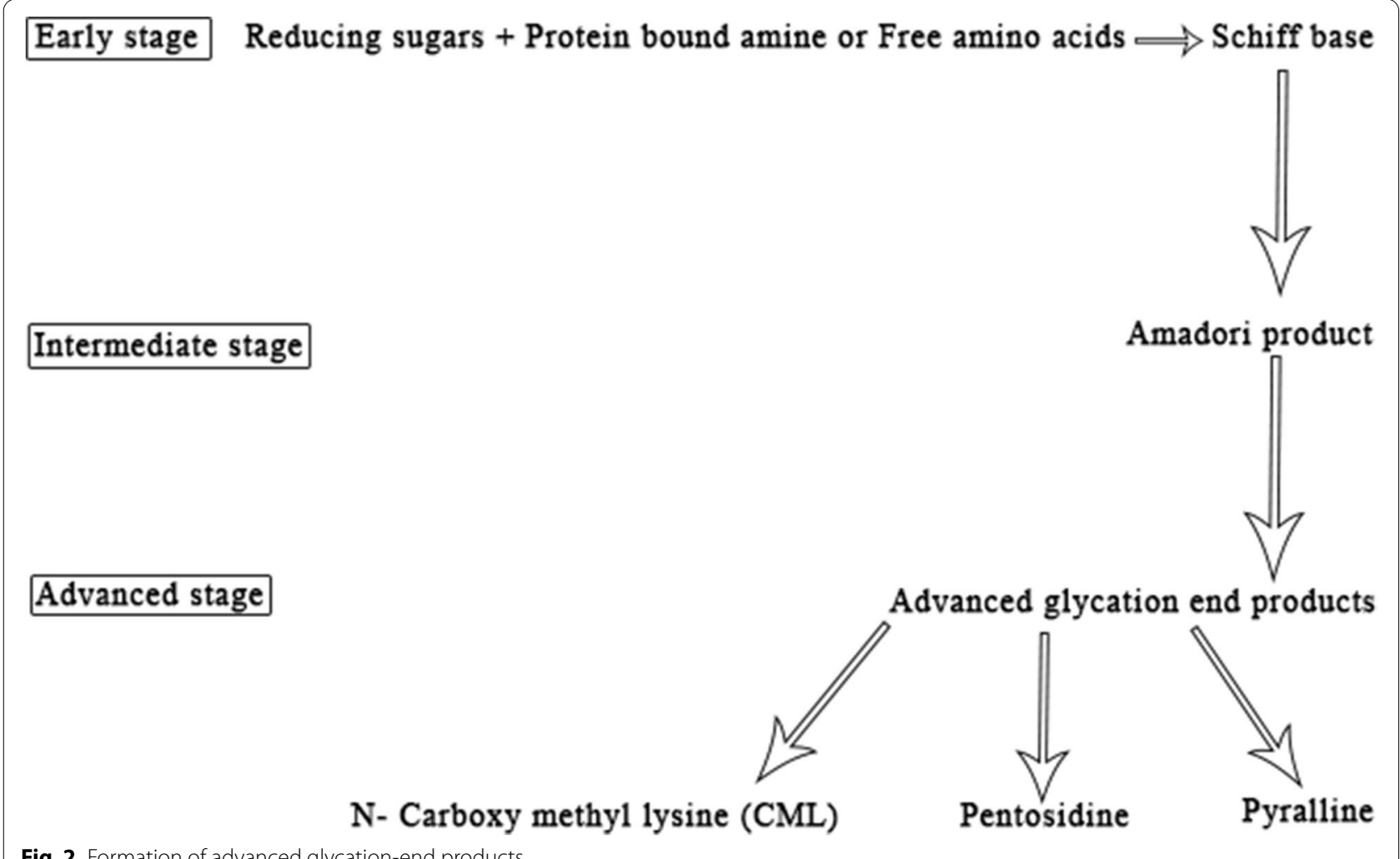

Fig. 2 Formation of advanced glycation-end products

is assumed that the glycation-based changes stabilize the affected region and protect it from degradation. In a recently conducted study on archaeological samples, results have shown that the age estimation by measuring the pentosidine levels has proven to be more accurate in comparison to D-Asp (Mahlke et al. 2021).

The advanced glycation-end products can be analyzed using fluorescence spectroscopy, mechanical indentation analysis, immunohistochemical staining, and immuneelectron microscopy (Miura et al. 2014), HPLC (Requena et al. 2003), gas chromatography-mass spectroscopy (GC-MS), and enzyme-linked immunosorbent assay (ELISA). However, various factors influence the accumulation of these products. Elevated blood glucose levels may lead to increased production of AGEs, which can be analyzed from tissues like the skin collagen, blood vessel walls, and interstitial connective tissue. Therefore, individuals with diabetes can give false high age estimates. Also, caries-affected teeth show higher values of pentosidine. More standardization is necessary for such samples.

\section{Lead accumulation}

Lead is considered as one of the most significant pollutants in the environment. The major sources of lead are through the industrial complexes that release lead into the environment through drinking water, fumes from car exhausts where leaded petrol is still in use, lead containing paints, leaded water pipes, and from traffic.

About $90 \%$ of lead is accumulated in the bones. The teeth, blood, and other soft tissues also contain considerable amount of lead which progressively increases with age. However, the blood lead levels are instantaneous, which reflect an immediate lead exposure (Steenhout and Pourtois 1981). In the bone, it is removed over time due to its remodeling, but in the teeth, once deposited, it cannot be removed as there is no turnover of apatite. Therefore, the teeth are the most suitable material for studying total past lead exposure (Grobler et al. 2000).

The concentration of lead has been used to study the pollutant levels primarily. However, lead levels in the teeth can also be utilized to analyze an individual's age due to its progressive accumulation (Bercovitz and Laufer 1991). In the teeth, dentin has been identified as the leading site for lead accumulation as compared with enamel (Gulson and Gillings 1997). A significant correlation between dentine lead levels and age was found in the Kuwaiti population and the difference between the real age and calculated age was $1.3+4.8$ years (Al-Qattan and Elfawal 2010). The lead is separated using anion exchange chromatography and measured 
using mass spectrophotometry, and atomic absorption spectrophotometry.

It is essential to note that the atmospheric lead levels influence the amount accumulated, making it population and region-specific. It may therefore be inapplicable as a generalized method for age estimation. Although if region-specific lead levels can be determined and correlated with age, this method can be employed.

\section{Mitochondrial DNA}

Mitochondrial DNA is present near the inner membrane of the mitochondria and is influenced by the presence of free radicals which accumulate with age. As stated by Harman in the theory of aging, the production of free radicals increases with age. This can be explained as an imbalance between pro-oxidants and anti-oxidants (Harman 1956). During the breakdown of enzymes in mitochondria, reactive oxygen species are produced. These cause damage to proteins, nucleic acids, and phospholipids. This leads to the synthesis of functionally impaired respiratory sub-units, causing mitochondrial DNA mutations that get accumulated with age and cause degenerative diseases (Horan et al. 2012). Such somatic, age-related mitochondrial DNA mutations may cause inefficient cell function, leading to several clinical manifestations, including renal dysfunction, cardiomyopathy, and neurological diseases (Papiha et al. 1998). Several studies have found a relation between mtDNA mutations and aging in tissues like the brain, skeletal muscle (Liu et al. 1998), and heart (Corral-Debrinski et al. 1992; Cortopassi et al. 1992). A semiquantitative PCR conducted on dentin and pulp of third molars demonstrated a decrease in the quantity of mtDNA with age (Mörnstad et al. 1999). In addition, a strong linear negative correlation has been seen between the amplification of mtDNA and dentin age using real-time PCR in third molars (Zapico and Ubelaker 2016).

The mtDNA damage is measured using real-time PCR. The process, however, is time-consuming, expensive, and technique-sensitive. The forensic implications of this method still need to be standardized for practical applications. The relation between the mutations and aging needs further evaluation for better applications in ancestry studies and to estimate age at death.

\section{Conclusions}

Among the above chemical methods, the most precise method is the racemization of the aspartic acid. Research for the standardization of sample collection, accuracy, and method reliability has been conducted in different parts of the world. The main advantage of using AAR is that the sample can be collected from tissues most protected from environmental and nutritional factors (teeth). If all the confounding factors are stable, the utilization of AGE products can also be considered valuable. However, these methods require studies focusing on providing a more standardized method. It is indispensable to note that all the above methods are invasive and involve the entire tooth destruction.

\section{Abbreviations \\ AAR: Aspartic acid racemization; EDTA: Ethylenediaminetetraacetic acid; AGE: Advanced glycation-end product; mtDNA: Mitochondrial DNA; HPLC: High power liquid chromatography; GC: Gas chromatography; IEC: Ion-exchange chromatography; GC-MS: Gas chromatography-mass spectroscopy; ELISA: Enzyme-linked immunosorbent assay.}

\section{Acknowledgements \\ Authors acknowledge the Vishnu Dental College, Bhimavaram, Andhra Pradesh, India.}

\section{Authors' contributions}

PM reviewed literature, collected data, and drafted manuscript. RM reviewed literature, collected data, and drafted manuscript. PS edited the data and made necessary corrections. SB edited the data and made necessary corrections. STA edited the data and made necessary corrections. The authors have read and approved the final manuscript.

\section{Funding \\ None.}

Availability of data and materials

Not required.

\section{Declarations}

Ethics approval and consent to participate

Not applicable.

\section{Consent for publication}

Not applicable.

\section{Competing interests}

The authors declare that they have no competing interests.

Received: 25 April 2021 Accepted: 12 December 2021

Published online: 11 January 2022

\section{References}

Alkass K, Buchholz BA, Ohtani S et al (2010) Age estimation in forensic sciences: application of combined aspartic acid racemization and radiocarbon analysis. Mol Cell Proteomics 9:1022-1030. https://doi.org/10.1074/ mcp.M900525-MCP200

Al-Qattan SI, Elfawal MA (2010) Significance of teeth lead accumulation in age estimation. J Forensic Leg Med 17:325-328. https://doi.org/10.1016/j.jflm. 2010.05.001

Bercovitz K, Laufer D (1991) Age and gender influence on lead accumulation in root dentine of human permanent teeth. Arch Oral Biol 36:671-673. https://doi.org/10.1016/0003-9969(91)90020-U

Brown SM, Smith DM, Alt N et al (2005) Tissue-specific variation in glycation of proteins in diabetes: evidence for a functional role of Amadoriase enzymes. Ann N Y Acad Sci 1043:817-823. https://doi.org/10.1196/annals. 1333.094

Brownlee M (1994) Lilly lecture 1993: glycation and diabetic complications. Diabetes 43:836-841

Cameriere R, Ferrante L, Belcastro MG et al (2007) Age estimation by pulp/ tooth ratio in canines by peri-apical X-rays. J Forensic Sci 52:166-170. https://doi.org/10.1111/j.1556-4029.2006.00336.x 
Collins MJ, Waite ER, Van Duin ACT (1999) Predicting protein decomposition: the case of aspartic-acid racemization kinetics. Phil Trans R Soc Lond B 354:51-64. https://doi.org/10.1098/rstb.1999.0359

Corral-Debrinski M, Shoffner JM, Lott MT, Wallace DC (1992) Association of mitochondrial DNA damage with aging and coronary atherosclerotic heart disease. Mutat Res 275:169-180. https://doi.org/10.1016/09218734(92)90021-G

Cortopassi GA, Shibata D, Soong NW, Arnheim N (1992) A pattern of accumulation of a somatic deletion of mitochondrial DNA in aging human tissues. Proc Natl Acad Sci U S A 89:7370-7374. https://doi.org/10.1073/ pnas.89.16.7370

Demirjian A, Goldstein H, Tanner JM (1973) Demirjian, A., A new system of dental age assessment, Human Biology, 45:2 (1973:May) p.211. Hum Biol 45:211-227

Dyer DG, Mccance DR, Baynes JW et al (1993) Accumulation of Maillard reaction products in skin collagen in diabetes and aging. Accumulation of Maillard Reaction Products in Skin Collagen in Diabetes and Aging. J Clin Invest 91:2463. https://doi.org/10.1172/JCl116481

Eyre D (1987) Collagen cross-linking amino acids. Methods Enzymol 144:115139. https://doi.org/10.1016/0076-6879(87)44176-1

Eyre DR, Koob TJ, Van Ness KP (1984) Quantitation of hydroxypyridinium crosslinks in collagen by high-performance liquid chromatography. Anal Biochem 137:380-388. https://doi.org/10.1016/0003-2697(84)90101-5

Eyre DR, Oguchi H (1980) The hydroxypyridinium crosslinks of skeletal collagens: their measurement, properties and a proposed pathway of formation. Biochem Biophys Res Commun 92:403-410. https://doi.org/ 10.1016/0006-291X(80)90347-2

Fu M, Jenkins AJ, Lyons TJ, Baynes JW (1996) The advanced glycation end product, N E-(carboxymethyl))ysine, is a product of both lipid peroxidation and glycoxidation reactions. J Biol Chem 271:9982-9986

Fujimoto D, Moriguchi T (1978) Pyridinoline, a non-reducible crosslink of collagen. Quantitative determination, distribution, and isolation of a crosslinked peptide. J Biochem. 83(3):863-867. https://doi.org/10.1093/ oxfordjournals.jbchem.a131983 PMID: 641035

Geiger T, Clarke S (1987) Deamidation, isomerization, and racemization at asparaginyl and aspartyl residues in peptides. Succinimide-linked reactions that contribute to protein degradation. J Biol Chem 262:785-794. https://doi.org/10.1016/S0021-9258(19)75855-4

Greis F, Reckert A, Fischer K, Ritz-Timme S (2018) Analysis of advanced glycation end products (AGEs) in dentine: useful for age estimation? Int I Legal Med 132:799-805. https://doi.org/10.1007/s00414-017-1671-x

Griffin RC, Moody H, Penkman KEH, Collins MJ (2008) The application of amino acid racemization in the acid soluble fraction of enamel to the estimation of the age of human teeth. Forensic Sci Int 175:11-16. https://doi.org/10. 1016/j.forsciint.2007.04.226

Griffin RC, Penkman KEH, Moody H, Collins MJ (2010) The impact of random natural variability on aspartic acid racemization ratios in enamel from different types of human teeth. Forensic Sci Int 200:148-152. https://doi. org/10.1016/j.forsciint.2010.04.005

Grobler SR, Theunissen FS, Kotze TJVW (2000) The relation between lead concentrations in human dental tissues and in blood. Arch Oral Biol 45:607-609. https://doi.org/10.1016/50003-9969(00)00024-8

Gulson BL, Gillings BR (1997) Lead exchange in teeth and bone - a pilot study using stable lead isotopes. Environ Health Perspect 105:820-824. https:// doi.org/10.1289/ehp.97105820

Harman D (1956) Aging: a theory on free radical radiation chemistry. J Gerontol 11:298-300

Hegde S, Patodia A, Dixit U (2017) A comparison of the validity of the Demirjian, Willems, Nolla and Häävikko methods in determination of chronological age of 5-15 year-old Indian children. J Forensic Leg Med 50:49-57. https://doi.org/10.1016/j.jfm.2017.07.007

Helfman PM, Bada JL (1975) Aspartic acid racemization in tooth enamel from living humans. Proc Natl Acad Sci U S A 72:2891-2894. https://doi.org/10. 1073/pnas.72.8.2891

Helfman PM, Bada JL (1976) Aspartic acid racemisation in dentine as a measure of ageing. Nature 262:279-281

Horan MP, Pichaud N, Ballard JWO (2012) Review: quantifying mitochondrial dysfunction in complex diseases of aging. J Gerontol - Biol Sci 67(A):1022-1035 https://doi.org/10.1093/gerona/glr263
Ilea A, Băbțan AM, Boşca BA et al (2018) Advanced glycation end products (AGEs) in oral pathology. Arch Oral Biol 93:22-30. https://doi.org/10. 1016/j.archoralbio.2018.05.013

Kaufman DS, Manley WF (1998) A new procedure for determining DL amino acid ratios in fossils using reverse phase liquid chromatography. Quat Sci Rev 17:987-1000. https://doi.org/10.1016/S0277-3791(97)00086-3

Kleter GA, Damen JJM, Buijs MJ, Ten CJM (1997) The Maillard reaction in demineralized dentin in vitro. Eur J Oral Sci 105:278-284. https://doi.org/10. 1111/j.1600-0722.1997.tb00212.x

Kleter GA, Damen JJM, Buijs MJ, Ten Cate JM (1998) Modification of amino acid residues in carious dentin matrix. J Dent Res 77:488-495. https://doi.org/ 10.1177/00220345980770030801

Klumb K, Matzenauer C, Reckert A et al (2016) Age estimation based on aspartic acid racemization in human sclera. Int J Legal Med 130:207-211. https://doi.org/10.1007/s00414-015-1255-6

Liu VWS, Zhang C, Nagley P (1998) Mutations in mitochondrial DNA accumulate differentially in three different human tissues during ageing. Nucleic Acids Res 26:1268-1275. https://doi.org/10.1093/nar/26.5.1268

Lyons TJ, Silvestri G, Dunn JA et al (1991) Role of glycation in modification of lens crystallins in diabetic and nondiabetic senile cataracts. Diabetes 40:1010-1015. https://doi.org/10.2337/diab.40.8.1010

Mahlke NS, Renhart S, Talaa D et al (2021) Molecular clocks in ancient proteins: do they reflect the age at death even after millennia? Int J Legal Med 135:1225-1233. https://doi.org/10.1007/s00414-021-02522-1

Martin-De Las Heras S, Valenzuela A, Villanueva E (1999) Deoxypyridinoline crosslinks in human dentin and estimation of age. Int J Legal Med 112:222-226. https://doi.org/10.1007/s004140050240

Mechanic G, Gallop PM, Tanzer ML (1971) The nature of crosslinking in collagens from mineralized tissues. Biochem Biophys Res Commun 45:644-653. https://doi.org/10.1016/0006-291X(71)90465-7

Minegishi S, Ohtani S, Noritake K et al (2019) Preparation of dentin standard samples for age estimation based on increased aspartic acid racemization rate by heating. Leg Med 38:25-31. https://doi.org/10.1016/j.legal med.2019.03.005

Miura J, Nishikawa K, Kubo M et al (2014) Accumulation of advanced glycation end-products in human dentine. Arch Oral Biol 59:119-124. https://doi. org/10.1016/j.archoralbio.2013.10.012

Mörnstad H, Pfeiffer H, Yoon C, Teivens A (1999) Demonstration and semiquantification of $m t D N A$ from human dentine and its relation to age. Int J Legal Med 112:98-100. https://doi.org/10.1007/s004140050209

Ogino T, Ogino H (1988) Application to forensic odontology of aspartic acid racemization in unerupted and supernumerary teeth. J Dent Res 67:1319-1322. https://doi.org/10.1177/00220345880670101501

Ogino T, Ogino H, Nagy B (1985) Application of aspartic acid racemization to forensic odontology: post mortem designation of age at death. Forensic Sci Int 29:259-267. https://doi.org/10.1016/0379-0738(85)90119-7

Ohtani S (1994) Age estimation by aspartic acid racemization in dentin of deciduous teeth. Forensic Sci Int 68:77-82. https://doi.org/10.1016/03790738(94)90305-0

Ohtani S, Ito R, Yamamoto T (2003) Differences in the D/L aspartic acid ratios in dentin among different types of teeth from the same individual and estimated age. Int J Legal Med 117:149-152. https://doi.org/10.1007/ s00414-003-0365-8

Ohtani S, Matsushima Y, Kobayashi Y, Yamamoto T (2002) Age estimation by measuring the racemization of aspartic acid from total amino acid content of several types of bone and rib cartilage: a preliminary account. J Forensic Sci 47:15202J. https://doi.org/10.1520/jfs15202j

Ohtani S, Sugimoto H, Sugeno H et al (1995) Racemization of aspartic acid in human cementum with age. Arch Oral Biol 40:91-95. https://doi.org/10. 1016/0003-9969(94)00156-6

Ohtani S, Yamamoto T (2010) Age estimation by amino acid racemization in human teeth. J Forensic Sci 55:1630-1633. https://doi.org/10.1111/j.15564029.2010.01472.x

Ohtani S, Yamamoto T, Abe I, Kinoshita Y (2007) Age-dependent changes in the racemisation ratio of aspartic acid in human alveolar bone. Arch Oral Biol 52:233-236. https://doi.org/10.1016/j.archoralbio.2006.08.011

Oimomi M, Igaki N, Hata F et al (1989) Age- and diabetes-accelerated glycation in the human aorta. Arch Gerontol Geriatr 8:123-127. https://doi.org/ 10.1016/0167-4943(89)90056-3

Ozveren N, Serindere G (2018) Comparison of the applicability of Demirjian and Willems methods for dental age estimation in children from the 
Thrace region, Turkey. Forensic Sci Int 285:38-43. https://doi.org/10. 1016/j.forsciint.2018.01.017

Papiha SS, Rathod H, Briceno I et al (1998) Age related somatic mitochondrial DNA deletions in bone. J Clin Pathol 51:117-120. https://doi.org/10.1136/ jcp.51.2.117

Rajkumari S, Nirmal M, Sunil PM, Smith AA (2013) Estimation of age using aspartic acid racemisation in human dentin in Indian population. Forensic Sci Int 228:38-41. https://doi.org/10.1016/j.forsciint.2013.02.021

Requena JR, Price DL, Thorpe SR, Baynes JW (2003) Measurement of pentosidine in biological samples. Aging Methods Protoc 38:209-217. https:// doi.org/10.1385/1-59259-070-5:209

Ritz S, Schutz HW, Schwarzer B (1990) The extent of aspartic acid racemization in dentin: a possible method for a more accurate determination of age at death? Zeitschrift for Rechtsmedizin 103:457-462. https://doi.org/10. 1007/bf01263154

Ritz S, Turzynski A, Schütz HW (1994) Estimation of age at death based on aspartic acid racemization in noncollagenous bone proteins. Forensic Sci Int 69:149-159. https://doi.org/10.1016/0379-0738(94)90251-8

Ritz-Timme S, Collins MJ (2002) Racemization of aspartic acid in human proteins. Ageing Res Rev 1:43-59. https://doi.org/10.1016/S0047-6374(01) 00363-3

Ritz-Timme S, Laumeier I, Collins M (2003) Age estimation based on aspartic acid racemization in elastin from the yellow ligaments. Int J Legal Med 117:96-101. https://doi.org/10.1007/s00414-002-0355-2

Robins SP, Shimokomakit M, Baileyt AJ (1973) The chemistry of the collagen cross-links

Schleicher E, Wieland OH (1986) Kinetic analysis of glycation as a tool for assessing the half-life of proteins. Biochim Biophys Acta 884:199-205. https://doi.org/10.1016/0304-4165(86)90244-8

Sell DR, Monnier VM (1990) End-stage renal disease and diabetes catalyze the formation of a pentose-derived crosslink from aging human collagen. J Clin Invest 85:380-384. https://doi.org/10.1172/JCl114449

Singh R, Barden A, Mori T, Beilin L (2001) Advanced glycation end-products: a review. Diabetologia 44:129-146. https://doi.org/10.1007/s001250051591

Sirin N, Matzenauer C, Reckert A, Ritz-Timme S (2018) Age estimation based on aspartic acid racemization in dentine: what about caries-affected teeth? Int J Legal Med 132:623-628. https://doi.org/10.1007/s00414-017-1667-6

Steenhout A, Pourtois M (1981) Lead accumulation in teeth as a function of age with different exposures. Br J Ind Med 38(3):297-303

Tessier FJ (2010) La réaction de Maillard dans le corps humain. Découvertes majeures et facteurs qui affectent la glycation. Pathol Biol 58:214-219. https://doi.org/10.1016/.jpatbio.2009.09.014

Vitek MP, Bhattacharya K, Glendening JM et al (1994) Advanced glycation end products contribute to amyloidosis in Alzheimer disease. Proc Natl Acad Sci 91:4766-4770. https://doi.org/10.1073/pnas.91.11.4766

Waite E, Collins M, Ritz-Timme S et al (1999) A review of the methodological aspects of aspartic acid racemization analysis for use in forensic science. Forensic Sci Int 103:113-124. https://doi.org/10.1016/S0379-0738(99) 00081-X

Walters C, Eyre DR (1983) Collagen crosslinks in human dentin: increasing content of hydroxypyridinium residues with age. Calcif Tissue Int 35:401-405. https://doi.org/10.1007/BF02405067

Wochna K, Bonikowski R, Śmigielski J, Berent J (2018) Aspartic acid racemization of root dentin used for dental age estimation in a Polish population sample. Forensic Sci Med Pathol 14:285-294. https://doi.org/10.1007/ s12024-018-9984-8

Zapico SC, Ubelaker DH (2016) Relationship between mitochondrial DNA mutations and aging. Estimation of age- At-death. Journals Gerontol Biol Sci 71:445-450. https://doi.org/10.1093/gerona/glv115

\section{Publisher's Note}

Springer Nature remains neutral with regard to jurisdictional claims in published maps and institutional affiliations. 